\title{
Passive films on nanocomposite carbide coatings for electrical contact applications
}

\author{
Kristian Nygren ${ }^{1,2, *}$ (D), Anna Mikaela Andersson ${ }^{3}$, Per Eklund $^{4}$ (D) , and Ulf Jansson ${ }^{1}$ \\ ${ }^{1}$ Department of Chemistry - Ångström Laboratory, Uppsala University, Box 538, 75121 Uppsala, Sweden \\ ${ }^{2}$ Impact Coatings $A B$, Westmansgatan 29, 58216 Linköping, Sweden \\ ${ }^{3} A B B$ Corporate Research, Forskargränd 7, 72178 Västerås, Sweden \\ ${ }^{4}$ Thin Film Physics Division, Department of Physics, Chemistry, and Biology (IFM), Linköping University, 58183 Linköping, Sweden
}

Received: 5 December 2016

Accepted: 24 March 2017

Published online:

3 April 2017

(C) The Author(s) 2017. This article is an open access publication

\begin{abstract}
Nanocomposite transition metal carbide/amorphous carbon coatings (Me-C/aC) deposited by magnetron sputtering have excellent electrical contact properties. The contact resistance can be as low as that of noble metal coatings, although it is known to vary by several orders of magnitude depending on the deposition conditions. We have investigated a nanocrystalline niobium carbide/ amorphous carbon $\left(\mathrm{NbC}_{x} / \mathrm{a}-\mathrm{C}: \mathrm{H}\right)$ model system aiming to clarify factors affecting the contact resistance for this group of contact materials. For the first time, the surface chemistry is systematically studied, by angle-resolved X-ray photoelectron spectroscopy, and in extension how it can explain the contact resistance. The coatings presented a mean oxide thickness of about $1 \mathrm{~nm}$, which could be grown to $8 \mathrm{~nm}$ by annealing. Remarkably, the contact resistances covered four orders of magnitude and were found to be exponentially dependent on the mean oxide thickness. Moreover, there is an optimum in the amount of a-C:H phase where the contact resistance drops very significantly and it is thus important to not only consider the mean oxide thickness. To explain the results, a model relying on surface chemistry and contact mechanics is presented. The lowest contact resistance of a nanocomposite matched that of a gold coating at $1 \mathrm{~N}$ load (vs. gold), and such performance has previously not been demonstrated for similar nanocomposite materials, highlighting their useful properties for electrical contact applications.
\end{abstract}

\section{Introduction}

Nanocomposite transition metal carbide/amorphous carbon coatings (Me-C/a-C) have properties that are interesting for electrical contact applications, where contact resistance, resistivity, tribological properties, corrosion resistance, operating temperature, durability, and cost are important parameters. As such, the high cost of noble metal coatings drives research toward cheaper alternatives. However, the precise

Address correspondence to E-mail: kristian.nygren@kemi.uu.se; kristian.nygren@impactcoatings.se 
requirements will depend upon the contact application which can vary from very small-scale electronics to large high-current switching contacts. Nanocomposite $\mathrm{Me}-\mathrm{C} / \mathrm{a}-\mathrm{C}$ coatings may be an alternative contact material in this range of applications. These nanocomposites contain nanocrystalline carbide grains embedded in an amorphous carbon matrix and can readily be deposited by magnetron sputtering on a wide range of substrates at fairly low temperatures $\left(<200^{\circ} \mathrm{C}\right)$. Some reported examples are binary systems such as $\mathrm{Ti}-\mathrm{C}[1,2], \mathrm{Cr}-\mathrm{C}$ [3], Nb-C $[4,5], \mathrm{V}-\mathrm{C}[6]$, and $\mathrm{Zr}-\mathrm{C}[6]$ as well as ternary Ti-Si-C $[7,8]$.

Holm's classical contact theory states that metalliclike conductive $a$-spots are formed upon mating of two contact members [9]. The current will be restricted to flow in these $a$-spots according to the resistivities of the members (constriction resistance) and the contact area, which is much smaller than the apparent contact area due to microtopography [10]. The mechanical contact area will then depend upon the hardness of the softest material, assuming a plastic deformation of the surfaces [11]. It is important to stress that this assumption excludes effects of contaminants [12]. For instance, the resistance of a surface layer can completely overshadow the constriction resistance [9], especially at low and intermediate loads where the contact resistance has been described by electron tunneling and a transient metallic contact, respectively [13]. In the latter stage, the fracturing of oxides is expected at a critical contact pressure with an abrupt decrease in contact resistance.

In relation to the nanocomposite coatings, three very important aspects can be identified. First, Timsit [14] described that classical contact theory breaks down when the $a$-spots shrink to some nanometers in size, which may be equivalent to the present case of nanocrystalline carbide grains, and hence, it is of interest to apply contact theory to examine its pertinence. Second, the contact member will no longer consist of just one material; a nanocomposite will behave differently than a bulk metal. For example, a nanocomposite can have high hardness, yet a comparatively low elastic modulus in relation to a metal $[15,16]$. In practice, the carbide nanocomposites are much harder than, for example, $\mathrm{Au}(\sim 5$ to $40 \mathrm{GPa}$ depending on type and fabrication method, compared to 1-2 GPa for $\mathrm{Au}$ [17]) and other metals normally used in electrical contacts. However, the presence of the carbon phase reduces the elastic modulus and adds low friction properties to the material, often improving the wear situation when compared to metallic coatings [18]. Third, nanocomposites will have an overlayer of, for example, a thin oxide, which can affect contact properties. Experimentally, Lewin et al. noted that nanocomposite coatings behaved differently than what could be predicted by theory $[1,6]$. In particular, the coatings resulted in different contact resistances depending on the amount of a-C phase, leading to the notion that an optimum carbon matrix thickness, separating the carbide grains, would lead to the lowest possible contact resistance. It was hypothesized that the nanocomposite films deformed more than pure carbide films and thereby caused more frequent penetration of the surface oxide, effectively resulting in more $a$-spots and a low contact resistance.

Several studies have stated that coating bulk properties, e.g., the coating microstructure, hardness, and resistivity, and the presence of surface oxides, affect contact properties at different contact loads $[1-5,7,8]$. Contact resistance has been measured at loads from $1 \mathrm{~N}$ up to $1000 \mathrm{~N}[1-5,7,8]$, however using different setups, and the influence from the coating bulk properties and the surface oxides on the contact properties are not easily decoupled. The phrasing "coating bulk" refers to the part of the coating that remains intact even after exposure to atmosphere. It excludes the thin layer of passive film formed after deposition. Notably, the surface chemistry of nanocomposites has never been systematically studied despite the known presence of oxides, e.g., 35-40 $\AA$ oxide on Ti-Si-C [19]. Moreover, it is not clear whether, and how, the presence of a-C phase influences the passive film, which in turn can affect the contact properties.

Consequently, factors influencing the contact behavior of carbide-based nanocomposites are not known. The aim of this study is to investigate in detail the relationship between microstructure, surface chemistry, and contact resistance of a model nanocomposite system. $\mathrm{Nb}-\mathrm{C}$ was chosen based on encouraging results in previous studies [4,5]. We have deposited coatings with different phase compositions and characterized the surface chemistry with X-ray photoelectron spectroscopy (XPS) to get a better understanding of the contact properties. 


\section{Experimental details}

Niobium carbide/carbon nanocomposite coatings with a thickness of $1 \mu \mathrm{m}$ were deposited by high-rate reactive unbalanced magnetron sputtering (InlineCoater ${ }^{\mathrm{TM}}$ 500, Impact Coatings $\mathrm{AB}$ ) from a $\mathrm{Nb}$ target in $\mathrm{Ar} / \mathrm{C}_{2} \mathrm{H}_{2}$ discharges. Metallic $\mathrm{Nb}$ coatings were also deposited as reference material. The base pressure was $1 \times 10^{-4} \mathrm{~Pa}$. The magnetron was operated in constant current mode at $20 \mathrm{~A}$ $\left(\sim 9 \mathrm{~W} \mathrm{~cm}^{-2}\right)$. The deposition rate in reactive mode was $3.7 \mathrm{~nm} \mathrm{~s}^{-1}$. Prior to each deposition, the target was sputter-cleaned. Small flat pieces, with close to mirror-like surface finish, of austenitic 316L stainless steel, Ni-plated bronze, $\mathrm{Si}$, and $\mathrm{SiO}_{2} / \mathrm{Si}$ were used as substrates and were placed on a stainless steel mesh situated $15 \mathrm{~cm}$ below the target. The $\mathrm{Si}$ and $\mathrm{SiO}_{2} / \mathrm{Si}$ substrates were only used for SEM cross sections and to measure sheet resistance, respectively. There was no substrate heating other than the heat induced by the coating process, with the exception of a few substrates heated to $200{ }^{\circ} \mathrm{C}$ as specified below in section "Surface characterization of coatings". All substrates were etched for $10 \mathrm{~s}$ by argon plasma at 1.9 Pa using a pulsed $(250 \mathrm{kHz})$ substrate bias $(650 \mathrm{~V})$. A $20-$ to $30-\mathrm{nm}$-thick $\mathrm{Nb}$ adhesion layer was deposited. The flow of acetylene was varied to obtain different coating composition. Spectral plasma intensity was monitored and suggested a stable process. Process pressures were 1.7 Pa (metallic) and $2.0 \mathrm{~Pa}$ (reactive), respectively. Post-coating annealing experiments in ambient atmosphere made use of a thick hot plate to very rapidly heat the samples to selected temperatures (up to $260{ }^{\circ} \mathrm{C}$ ) and to steadily keep them there for $15 \mathrm{~min}$. A thermocouple was used to verify sample temperature. Rapid cooling was achieved by relocating the samples to a separate aluminum block. The purpose of annealing was to influence surface chemistry.

Cross-sectional micrographs were obtained from fractured samples using a Zeiss Leo 1550 field emission scanning electron microscope (SEM). Coating microstructure was studied by $\mathrm{X}$-ray diffraction (XRD) using a Philips X'pert diffractometer equipped with $\mathrm{Cu} \mathrm{K} \alpha$ radiation. Grazing incidence scans and $\theta-$ $2 \theta$ scans were performed. Estimated grain sizes were obtained from the broadening of diffraction peaks by applying the Scherrer approximation and the Williamson-Hall plot methodology [20]. The latter accounts for inhomogeneous strain broadening by acknowledging that size broadening and strain broadening have different relationships to the diffraction angle. Both methods require that instrumental broadening is known and it is obtained from peaks of more crystalline material (i.e., not nano) in a strain-free state. Composition and chemical bonding were determined by X-ray photoelectron spectroscopy (XPS) using a Physical Electronics Quantum 2000 Scanning ESCA Microprobe with monochromatic $\mathrm{Al} \mathrm{K} \alpha$ radiation. To calculate chemical composition, the instrument standard sensitivity factors were used. The analysis spot size was $200 \mu \mathrm{m}$. Spectra in the $\mathrm{C} 1 \mathrm{~s}, \mathrm{O} 1 \mathrm{~s}$, and $\mathrm{Nb3d}$ regions were acquired at pass energies of $11.75,29.35$, or $58.70 \mathrm{eV}$ depending on desired resolution and intensity. The higher pass energies were used to reduce analysis time during time-consuming angular-resolved measurements and sputter depth profiling. Sensitivity factors were mathematically corrected for the different pass energies according to instrument documentation. Hydrogen incorporation was not determined but may have existed as $\mathrm{C}-\mathrm{H}$ bonds. LorentzianGaussian sum functions were used to fit intensity on a Shirley background (software XPSPEAK v4.1). The C1s region was fitted by peaks for $\mathrm{C}-\mathrm{Nb}(282.7-$ $282.9 \mathrm{eV})$ and $\mathrm{C}-\mathrm{C}\left(s p^{2} 284.4 \mathrm{eV}, s p^{3} 285.3 \mathrm{eV}\right)[3,21]$ bonds (always after sputter removal of adventitious hydrocarbons). The O1s region was fitted by peaks for $\mathrm{O}-\mathrm{Nb} \quad(530.2 \mathrm{eV}), \mathrm{O}-\mathrm{C}(\sim 531.7)$, and $\mathrm{O}=\mathrm{C}$ $(\sim 533.2 \mathrm{eV})$, where the two latter fits could be used to verify the removal of adventitious hydrocarbons $[22,23]$. The $\mathrm{Nb3d}$ region was fitted by peaks for $\mathrm{Nb}-$ $\mathrm{Nb}(202.6 \pm 0.1 \mathrm{eV}), \mathrm{Nb}-\mathrm{O}(\equiv 207.4 \mathrm{eV})$, and $\mathrm{Nb}-\mathrm{C}$ $(204.1 \pm 0.1 \mathrm{eV})$ bonds, including their spin-orbit splits $(+2.72 \mathrm{eV}$, equal FWHM, area ratio 2:3) [24]. The $\mathrm{Nb}-\mathrm{Nb}$ and $\mathrm{Nb}-\mathrm{C}$ fits had highly asymmetric modifiers for the shape and tail and will be further discussed below as well as the possibility of additional chemical species. Angle-resolved XPS (ARXPS) was performed at emission angles of $15^{\circ}, 30^{\circ}, 45^{\circ}$, and $60^{\circ}$ relative to the surface. For ARXPS, the acceptance angle was reduced to $4^{\circ}$ (from the standard of $20^{\circ}$ ) to improve angular resolution, and no sputter etching was performed. Analysis times were proportionally extended to compensate for the intensity decrease with sine of the angle. The standard emission angle was $45^{\circ}$. Electron attenuation lengths were calculated as described elsewhere [25]. Depth profiling was performed by $\mathrm{Ar}^{+}$sputter etching on an area of $1 \times 1 \mathrm{~mm}^{2}$. The ion energy was 500 or $1000 \mathrm{eV}$ 
depending on the intention of the analysis in question. The measurement error of composition and phase content by XPS is typically a few percentage.

Sheet resistance was measured using a four-point tungsten carbide probe (Jandel Engineering) connected to a multimeter (Agilent Technologies $34420 \mathrm{~A}$ ) and a parallel resistor model to evaluate resistivity. The contact resistance was measured in a setup suited for the investigation of materials for low voltage and low contact force electronics, shown in Fig. 1. A sample was mounted on a translational stage controlled by a servo connected to stepper motors (C-863 Mercury Servo Controller and M-111.1DG stages, Physik Instrumente). The stage was moved upwards to establish physical contact with a counterpart, which consisted of a spring-loaded cylindrical test probe with a hemispherical tip (1.2 $\mathrm{mm}$ diameter) and gold plating. Contact load was measured by a force gauge $( \pm 0.01 \mathrm{~N}, \mathrm{FG}-5000 \mathrm{~A}$, Lutron Electronics) and typically ranged from $\sim 0.1$ to $1 \mathrm{~N}$. Contact resistance was measured by a 4 -wire multimeter (Agilent Technologies 34401A) by applying a current of $1 \mathrm{~mA}$ and measuring the voltage drop across the junction. Two leads were attached to the (coated) substrate by crocodile clips, the lead connected to the probe tip was soldered, and the final lead was mechanically attached to the top of the probe via a clamping frame and a tooth washer. Internal resistance in the probe was constant and low. Gold-coated reference samples were used to verify that the probe was in good condition. The probe was cleaned with isopropanol before each measurement.

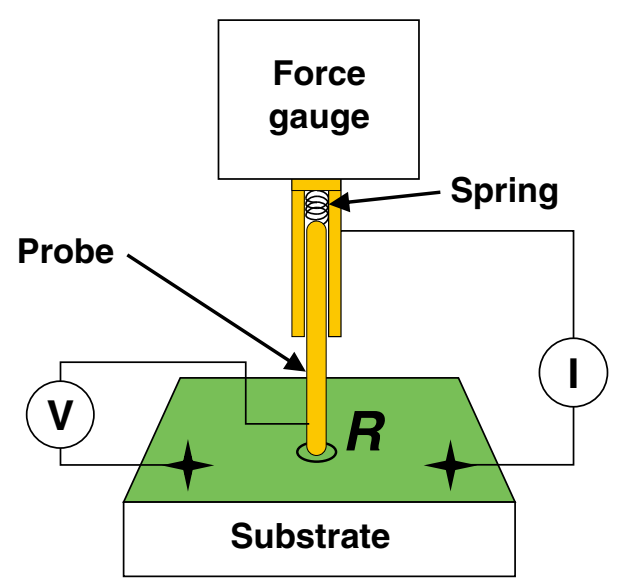

Figure 1 The setup to measure electrical contact resistance $(R)$. It is further described in experimental details.

\section{Results and discussion}

\section{Microstructure and composition of the coating bulk}

Coatings with different atomic ratios of carbon to niobium $(\mathrm{C} / \mathrm{Nb})$ were deposited by reactive magnetron sputtering with a range in $\mathrm{C} / \mathrm{Nb}$ from 0 to 1.6. Four cross-sectional micrographs are shown in Fig. 2. They are examples to illustrate that the coatings were of good quality, apparently free from pinholes and particles. Their uniform appearance across the whole thickness, nominally $1 \mu \mathrm{m}$, is typical of a stable deposition process. The thin $\mathrm{Nb}$ adhesion layer of 20-30 nm is just barely visible in Fig. 2. A columnar structure is observed at a low $\mathrm{C} / \mathrm{Nb}$ ratio $(<0.8)$, and while it is more refined at higher ratios (1.0), the
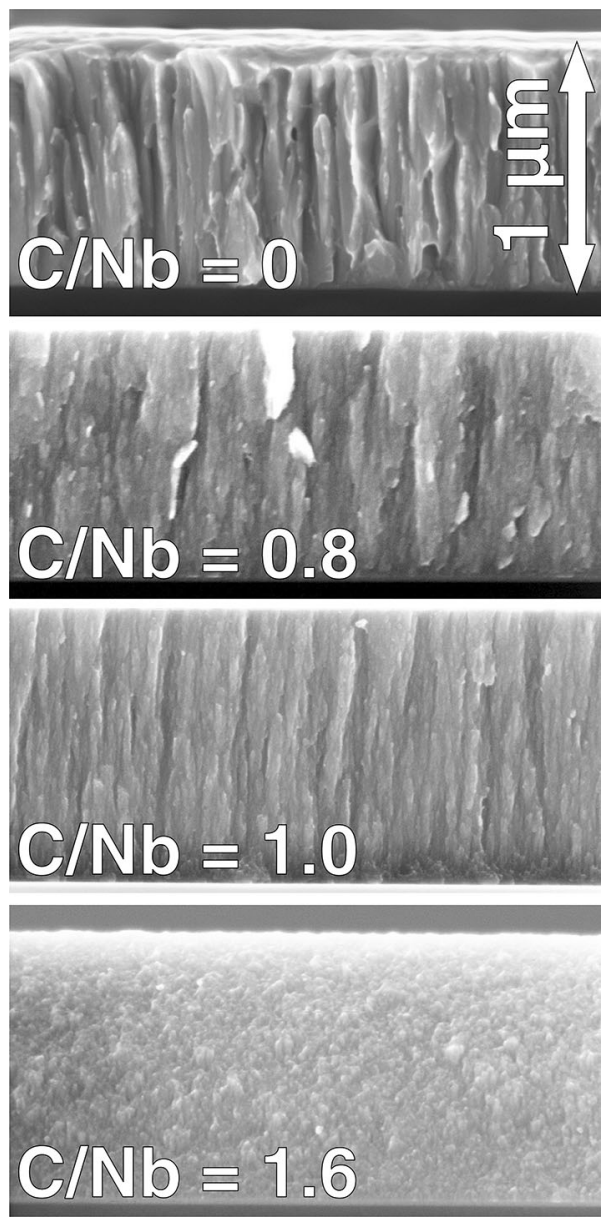

Figure 2 Cross-sectional micrographs of $\mathrm{Nb}-\mathrm{C}$ coatings of $1 \mu \mathrm{m}$ thickness deposited on Si substrates. There was a 20-nm-thick Nb adhesion layer as well, but it is barely visible. Carbon/niobium atomic ratios $(\mathrm{C} / \mathrm{Nb})$ represent the bulk composition obtained by XPS after sputter etching. 
coatings finally appear rather featureless at the highest ratios (1.6). This trend in columnar growth is typical of transition metal carbides deposited by sputtering at low temperature and low substrate bias. It should be noted that the widths of the columns do not represent grain size and are more of a morphological growth characteristic.

Grazing incidence (GI) X-ray diffractograms, corresponding to coatings with the four different $\mathrm{C} / \mathrm{Nb}$ ratios, are shown in Fig. 3. For the pure $\mathrm{Nb}$ metal $(\mathrm{C} /$ $\mathrm{Nb}=0$ ), the observed $\mathrm{Nb}(110), \mathrm{Nb}(200)$, and $\mathrm{Nb}(211)$ peaks correspond to a fcc phase with lattice parameter of $3.292 \AA$, in good agreement with the bulk value of $3.300 \AA$ [26]. For the carbon-containing films, the fcc $\mathrm{NbC}$ peaks were observed as well as austenitic substrate peaks $(\gamma)$. Importantly, these peaks did not overlap with the $\mathrm{NbC}$ peaks, with the exception of the one corresponding to $\mathrm{NbC}(222)$, which was very weak and not used for further analysis. The $\mathrm{NbC}$ peaks were rather broad, indicating carbide grains with nanocrystalline sizes, and the peak broadening increased for higher $\mathrm{C} / \mathrm{Nb}$ ratios, further indicating a successive decrease in grain size (assuming negligible internal stress). There were also slight shifts in the peak positions, corresponding to lattice parameters of $4.488 \AA, 4.477 \AA$, and $4.469 \AA$ for the $\mathrm{C} / \mathrm{Nb}$ ratios of $1.6,1.0$, and 0.8 , respectively. In comparison, the bulk $\mathrm{NbC}_{1.00}$ lattice parameter [27] of $4.474 \AA$ is in the middle of the obtained range, which is explained by XPS analysis and will be discussed below.

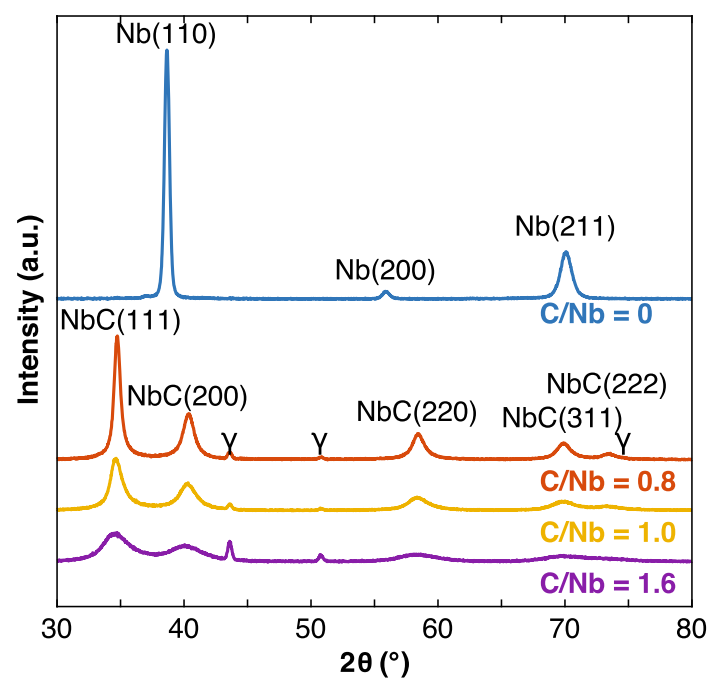

Figure 3 X-ray diffractograms at grazing incidence $\left(1^{\circ}\right)$ for $\mathrm{Nb}-\mathrm{C}$ coatings (ICDD PDF card no. 38-1364) with different $\mathrm{C} / \mathrm{Nb}$ ratios deposited on austenitic $(\gamma)$ stainless steel substrates.
The diffraction peaks in Fig. 3 could be modeled by pseudo-Voigt functions, and because of differences in line shapes, the broadening was defined as the integral breadth (i.e., fitted peak area/height) instead of the (common) full width at half maximum. With significant strain broadening accounted for (using Williamson-Hall plots), the lower bound estimates for the carbide grain sizes were $2 \mathrm{~nm}(\mathrm{C} / \mathrm{Nb}=1.6)$, $4 \mathrm{~nm}(\mathrm{C} / \mathrm{Nb}=1.0)$, and $12 \mathrm{~nm}(\mathrm{C} / \mathrm{Nb}=0.8)$. This decrease in grain size with increase in carbon content is commonly observed for nanocrystalline carbide coatings [28]. For the $\mathrm{Nb}$ coating, the estimated grain size was $20 \mathrm{~nm}$, as given by the Scherrer equation due to few peaks and unreliable linear regression of the Williamson-Hall plot.

The compositions of the coatings were obtained from XPS Nb3d and C1s spectra, acquired after sputter etching (500 $\mathrm{eV} \mathrm{Ar}^{+}$) to remove all surface oxides and adsorbed species. Figure $4 \mathrm{a}$ shows the C1s spectra, where two peaks at 284.4 and $282.2 \mathrm{eV}$ can be identified. They are attributed to $\mathrm{C}-\mathrm{C}$ in a hydrogenated amorphous carbon phase $(\mathrm{a}-\mathrm{C}: \mathrm{H})$ and $\mathrm{C}-\mathrm{Nb}$ in a carbide phase $\left(\mathrm{NbC}_{x}\right)$, respectively $[4,5,29]$. The relative amounts of the two phases can then be calculated from the relative peak areas. Up to $47 \%$ of the intensity in C1s corresponded to C-C
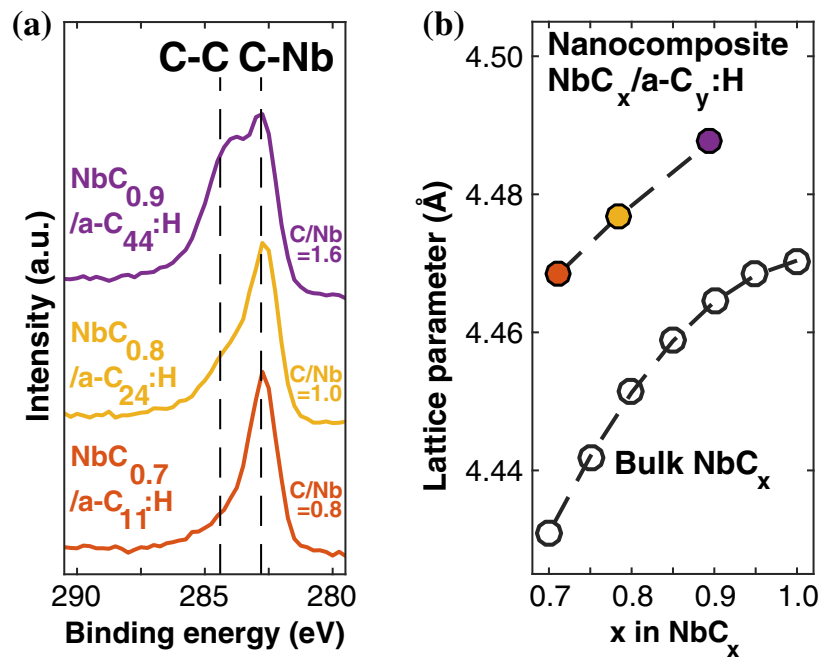

Figure 4 a $\mathrm{C} 1 \mathrm{~s}$ XPS spectra for the $\mathrm{NbC}_{x} / \mathrm{a}-\mathrm{C}_{y}: \mathrm{H}$ coatings. The peak areas of the $\mathrm{C}-\mathrm{C}$ and $\mathrm{C}-\mathrm{Nb}$ features (peak fits not shown) relative to the total $\mathrm{C} 1 \mathrm{~s}$ intensity give the relative contents (\%) of a-C:H (i.e., the value y) phase and $\mathrm{NbC}_{x}$ phase, respectively. The value of $x$ is obtained by dividing the total $\mathrm{C}-\mathrm{Nb}$ content (at.\%) by the niobium content (at.\%). b The lattice parameter of the fcc $\mathrm{NbC}_{x} / \mathrm{a}-\mathrm{C}_{y}: \mathrm{H}$ coatings versus the value of $x$. Literature data for bulk $\mathrm{NbC}_{x}$ adapted from Storms and Krikorian [30]. 
bonds (for the most carbon-rich coatings) and conversely the remaining intensity corresponded to $\mathrm{C}-$ $\mathrm{Nb}$ bonds. These fractions were highly correlated with the total $\mathrm{C} / \mathrm{Nb}$ ratio in the coating, meaning that more carbon in the coating leads to a higher fraction of a-C:H. The oxygen content was 3-6 at.\%.

By combining the XRD and XPS results, the coatings can be described as nanocomposites with nanocrystalline $\mathrm{NbC}_{x}$ grains in an a-C:H matrix. The value of $x$ in $\mathrm{NbC}_{x}$ was then obtained from the $\mathrm{Nb}$ content and the fraction of carbidic carbon. For convenience, coatings may hereafter be referred to by the designation $\quad \mathrm{NbC}_{x} / \mathrm{a}-\mathrm{C}_{y}: \mathrm{H}$, e.g., $\mathrm{NbC}_{0.8} / \mathrm{a}-\mathrm{C}_{15}: \mathrm{H}$ which means a coating with sub-stoichiometric fcc $\mathrm{NbC}_{0.8}$ phase and that $15 \%$ of the carbon atoms were located in the a-C:H phase. As shown in Fig. 4a, the carbide composition in the three coatings was in the range $\mathrm{NbC}_{0.7-0.9}$ and $11-44 \%$ of all carbon atoms were present as a-C:H phase. Moreover, the variations in lattice parameters could be explained. The lattice parameters derived above have been plotted versus the value of $x$ in $\mathrm{NbC}_{x}$ in Fig. $4 \mathrm{~b}$, in which the lattice parameter appears proportional to value of $x$. Compared to bulk values for $\mathrm{NbC}_{x}$ (also included in Fig. 4) [30], the lattices were concluded to have expanded. This expansion can be explained by a transfer of charge, from metal atoms residing on the surface of the nanocrystalline carbide grains $(<150 \AA)$ to carbon atoms in the carbon phase, which weakens the metal-carbon bond and leads to a carbide lattice expansion [31]. Note that the experimental shifts observed in XRD (leading to the different lattice parameters) can in principle also be caused by compressive stress. However, such effects can be deemed insignificant based on works by Lewin et al. [31], showing that the expansion effect is real.

The mean thickness of the a-C(:H) matrix, essentially separating the carbide grains, can be roughly estimated by assuming a cube model and associated equations [28, 32]. In this model, the carbide grains are represented by equally sized cubes placed on a three-dimensional grid with matrix phase filling the space between the cubes. Numerical input parameters were the grain sizes given by $\mathrm{XRD}$, the phase fractions of $\mathrm{NbC}_{x}$ and a-C:H given by XPS, and the densities for $\mathrm{NbC}_{x}\left(7.4-7.6 \mathrm{~g} \mathrm{~cm}^{-3}\right.$ [5]) and a-C:H $\left(1.6 \mathrm{~g} \mathrm{~cm}^{-3}\right.$ [33]). The calculations resulted in an estimated matrix thickness of $0.28,0.23$, and $0.21 \mathrm{~nm}$ for the coatings with $\mathrm{C} / \mathrm{Nb}$ ratios of $0.8,1.0$, and 1.6, respectively. Note that in the previous study on $\mathrm{Nb}-$
C nanocomposites [5], the matrix thickness was determined to be in the range $0.20-0.41 \mathrm{~nm}$ for similar $\mathrm{C} / \mathrm{Nb}$ ratios, without any trend. Therefore, the presently obtained thicknesses can be averaged into a mean matrix thickness of $0.24 \mathrm{~nm}$, representative of all coatings. Note that the cube model does not account for anisotropy, which is quite common in thin-film deposition. For example, in the case of columnar film growth, the a-C can preferentially accumulate in the boundaries between the columns rather than more evenly distribute around the carbide grains. Nonetheless, it is a relevant method and the matrix thickness can be used to explain coating properties, especially for different material systems and when the differences in the matrix thicknesses are larger.

\section{Surface characterization of coatings}

It was found that even very gentle sputter etching, intended to remove adventitious carbon contamination, degraded the parts of the Nb3d XPS spectra. Therefore, instead of sputter etching, angle-resolved measurements (ARXPS) were carried out at different acquisition angles. Note that the presence of a thin adsorbed layer of hydrocarbons does not affect oxide thickness calculations. The Nb3d peaks from as-deposited $\mathrm{Nb}$ and $\mathrm{NbC}_{0.8} / \mathrm{a}-\mathrm{C}: \mathrm{H}$ coatings are shown in

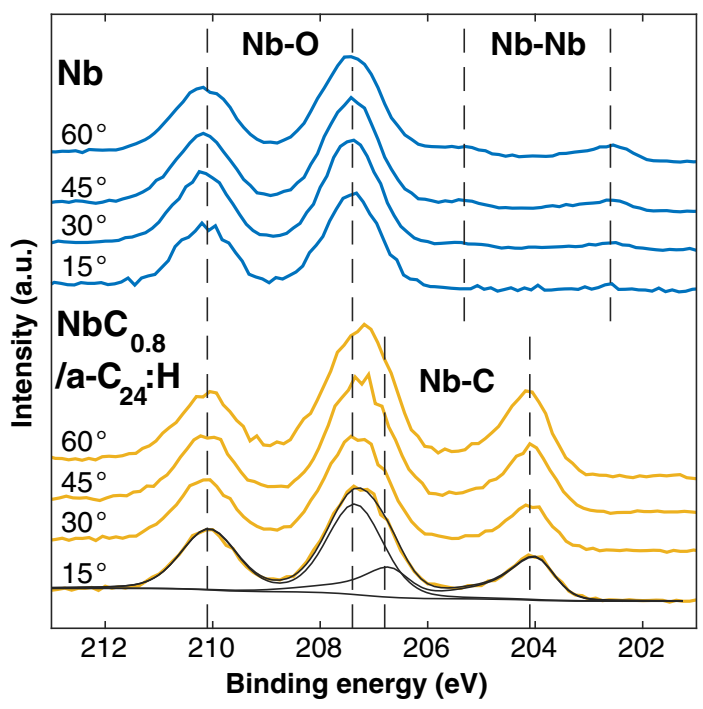

Figure 5 Angle-resolved XPS Nb3d surface spectra for metallic $\mathrm{Nb}$ and nanocomposite $\mathrm{NbC}_{0.8} / \mathrm{a}_{-} \mathrm{C}_{24}: \mathrm{H}$ coatings. Peak fits for $\mathrm{Nb}-$ $\mathrm{C}$ and $\mathrm{Nb}-\mathrm{O}$ bonds, as well as background, are shown under the spectrum at the bottom. Intensity is normalized to $\mathrm{Nb}-\mathrm{O}$ at $210.1 \mathrm{eV}$. Analysis at low angle was more surface sensitive. 
Fig. 5. In these spectra, a higher angle will map more into the bulk, and as the angle decreases, the analysis becomes more surface sensitive with an information depth of $2.3 \mathrm{~nm}$ at $15^{\circ}\left(\lambda=3 \mathrm{~nm}\right.$ for $\mathrm{Nb}_{2} \mathrm{O}_{5}$, Ref. [34]). As can be seen, the Nb3d peaks have a spinorbit split $\left(3 d_{5 / 2}-3 d_{3 / 2}\right)$ separated by $2.72 \mathrm{eV}$. Contributions from $\mathrm{Nb}-\mathrm{Nb}$ bonds $(202.2 \mathrm{eV}), \mathrm{Nb}-\mathrm{C}$ bonds $(203.7 \mathrm{eV})$, and $\mathrm{Nb}-\mathrm{O}$ bonds (202.9-207.55 eV, where $\mathrm{Nb}$ can be in oxidation numbers $\mathrm{I}-\mathrm{V}$ ) and from oxycarbide $\mathrm{NbC}_{x} \mathrm{O}_{y}(204.4-205.8 \mathrm{eV})$, can be expected based on the works of Grundner and Halbritter [34] as well as Darlinski and Halbritter [35] who studied corresponding bulk materials. In a separate communication, Halbritter and Darlinski [24] acknowledged the issue with fitting multiple doublets in a narrow energy range but concluded that all of the contributions were necessary to describe the chemistry in the interface. However, they also stated that the percentage of the suboxides was very small and that these bonds did not appear as separate peaks. Oxycarbide formation (i.e., carbide with oxygen in interstitial sites) could not be resolved according to the Nb3d XPS study [35]. Correspondingly, we were also unable to experimentally resolve any peaks due to suboxides or oxycarbide. Nevertheless, in attempts to fit the spectra with additional peak shapes for those chemical species, the areas of those peak fits were simply correlated with the area of the $\mathrm{Nb}-\mathrm{C}$ fit. To establish a suitable general peak fit model, we assumed that all coatings had some pentoxide $\mathrm{Nb}_{2} \mathrm{O}_{5}$ on top of the surface and the acquired spectra were then energy calibrated relative to the $3 \mathrm{~d}_{3 / 2}$ peak of $\mathrm{Nb}_{2} \mathrm{O}_{5}$ defined at $210.1 \mathrm{eV}$ (which was always abundant and well resolved). Lorentzian-Gaussian functions were used to represent $\mathrm{Nb}_{2} \mathrm{O}_{5}$ at $207.4 \mathrm{eV}$, $\mathrm{Nb}-\mathrm{C}$ at $204.2 \mathrm{eV}$, and $\mathrm{Nb}-\mathrm{Nb}$ at $202.5 \mathrm{eV}$. The fits were in good agreement with the cited studies $[34,35]$ except for the present addition of a strong asymmetric tail modifier for the conducting compounds $\mathrm{Nb}-\mathrm{C}$ and $\mathrm{Nb}-\mathrm{Nb}$. The reason for the modifier is to account for $\mathrm{Nb3d}$ asymmetry and limit the number of model bands [36]. By using this fitting strategy, there was no need for any additional peak fits to account for the experimental data. No metallic $\mathrm{Nb}-\mathrm{Nb}$ was observed in the $\mathrm{Nb3d}$ spectra, neither before nor after sputter etching, obtained from the $\mathrm{NbC}_{x} / \mathrm{a}-\mathrm{C}_{y}: \mathrm{H}$ coatings.

In Fig. 5, all spectra have been intensity-normalized relative to the $\mathrm{Nb}-\mathrm{O}$ peak at $210.1 \mathrm{eV}$. As can be seen, the relative intensities of the $\mathrm{Nb}-\mathrm{Nb}$ and $\mathrm{Nb}-\mathrm{C}$ peaks are reduced with decreasing acquisition angle, and this proves that the surface layers contain more $\mathrm{Nb}_{2} \mathrm{O}_{5}$ close to the surface. In terms of bond fractions at the most surface-sensitive angle $\left(15^{\circ}\right)$, the niobium had about $95 \% \mathrm{Nb}-\mathrm{O}$ bonds, and the nanocomposites had about $70 \%$. At the most bulk-sensitive angle $\left(60^{\circ}\right)$, the niobium had about $85 \% \mathrm{Nb}-\mathrm{O}$, and the nanocomposites had about $45 \%$. These results strongly indicate a thinner oxide layer for the nanocomposite coatings compared to the $\mathrm{Nb}$ coating.

A simple strategy to evaluate the thickness of the pentoxide from the intensity fractions was to assume a perfectly flat and homogeneous oxide overlayer on a substrate, where the oxide thickness is then given by Eq. 1

$d_{\mathrm{ox}}=\lambda_{\mathrm{ox}} \sin \theta \ln \left(\frac{I_{\mathrm{ox}}}{I_{\mathrm{u}}}+1\right)$

where $d_{\text {ox }}$ is the thickness of the oxide, $\lambda_{\text {ox }}$ is the attenuation length for electrons with a specific kinetic energy (in this case corresponding to Nb3d electrons ejected by $\mathrm{Al} \mathrm{K \alpha} \mathrm{X}$-rays and traveling through $\mathrm{Nb}_{2} \mathrm{O}_{5}$ compound), $\theta$ is the emission angle, $I_{\mathrm{ox}}$ is the intensity from the oxide, and $I_{\mathrm{u}}$ is the intensity from the underlying layer $(\mathrm{Nb}$ or $\mathrm{NbC})[37,38]$. Figure 6 shows calculated mean oxide thicknesses for different coatings assuming an attenuation length of $3.0 \mathrm{~nm}$. Values are about 1 and $4 \mathrm{~nm}$ for the nanocomposites and the metal, respectively, and these values are similar to those reported for bulk compounds [24, 37]. However, the results have a pronounced angular dependence which implies that the analysis was affected by serration as a perfectly

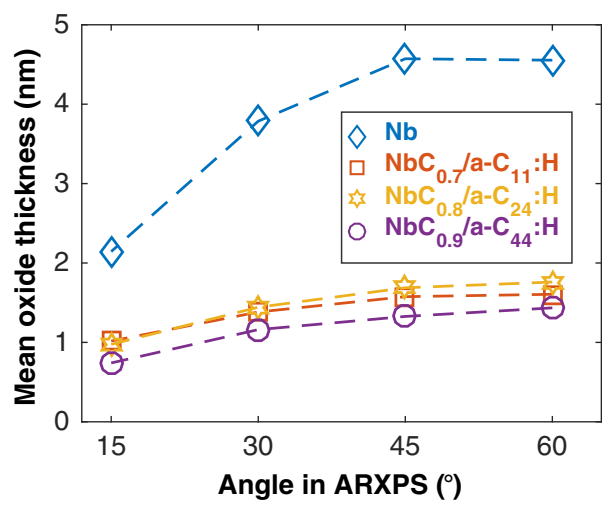

Figure 6 The mean oxide thickness, calculated from ARXPS data using Eq. 1 for metallic $\mathrm{Nb}$ and nanocomposite $\mathrm{NbC}_{x} / \mathrm{a}-\mathrm{C}_{y}: \mathrm{H}$ coatings. Angle dependency was due to serration. Analysis at low angle was more surface sensitive. 
layered system would yield a constant thickness. Essentially, this means that the oxide overlayer is not perfectly flat. This type of serration was also observed by Darlinski and Halbritter in their ARXPS studies of $\mathrm{Nb}$ and $\mathrm{NbC}$ [35].

The ARXPS data were further analyzed to find out whether the carbide and oxide phases had any kind of depth-dependent stoichiometries. Regarding the carbide, the total amount of $\mathrm{C}$ with $\mathrm{C}-\mathrm{Nb}$ bond (at.\%) and the total amount of $\mathrm{Nb}$ with $\mathrm{Nb}-\mathrm{C}$ bond (at.\%), calculated from the obtained $\mathrm{C} 1 \mathrm{~s}$ and Nb3d spectra, were plotted against each other (not shown here). The data formed a distinct straight line, and there were consequently no signs of stoichiometric changes as a function of depth. The slope of the line was 0.84, which essentially is the average bulk composition of the carbide phase in the three coatings and matched the bulk analysis discussed above. Regarding the oxide, an analogous plotting procedure used the total amounts of $\mathrm{O}-\mathrm{Nb}$ versus $\mathrm{Nb}-\mathrm{O}$ (not shown here). In this case, the data also formed a straight line and the regression slope was 2.44 , which corresponds to that of $\mathrm{Nb}_{2} \mathrm{O}_{5}$.

To enforce greater differences in surface oxidation, annealing experiments were carried out in ambient atmosphere on a hot plate at temperatures from 80 to $260{ }^{\circ} \mathrm{C}$ for $15 \mathrm{~min}$. Such conditions mainly targeted the surface chemistry and should not have allowed for any bulk recrystallization [39]. Figure 7 shows the

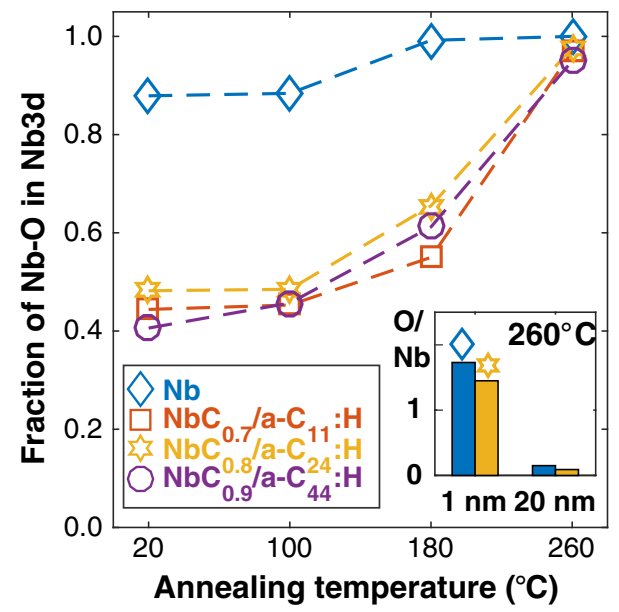

Figure 7 The fraction of $\mathrm{Nb}-\mathrm{O}$ bonds in XPS Nb3d spectra versus annealing temperature for metallic $\mathrm{Nb}$ and nanocomposite $\mathrm{NbC}_{x} / \mathrm{a}-\mathrm{C}_{y}: \mathrm{H}$ coatings. The remaining fraction was $\mathrm{Nb}-\mathrm{C}$ bonds $(\approx 0-0.6)$ or $\mathrm{Nb}-\mathrm{Nb}$ bonds $(\approx 0-0.1)$. Insets show $\mathrm{O} / \mathrm{Nb}$ atomic ratio after $\mathrm{Ar}^{+}$sputter etching for metallic $\mathrm{Nb}$ and nanocomposite $\mathrm{NbC}_{0.8} / \mathrm{a}-\mathrm{C}_{24}: \mathrm{H}$, and it demonstrates that the oxide did not extend deep into the samples even after annealing at $260{ }^{\circ} \mathrm{C}$. fractions of $\mathrm{Nb}-\mathrm{O}$ bonds based on $\mathrm{Nb3d}$ spectra (acquired without any sputter etching) as a function of annealing temperature. The different series correspond to the different coatings, and once again, the difference between the metal and the nanocomposites was very distinct. The series for the $\mathrm{Nb}$ coating shows around $90 \% \mathrm{Nb}-\mathrm{O}$ at temperatures of $20-100{ }^{\circ} \mathrm{C}$ and close to $100 \%$ at $180-260{ }^{\circ} \mathrm{C}$. In contrast, the series for the nanocomposite coatings form overlapping trends and these show about $45 \% \mathrm{Nb}-\mathrm{O}$ up to temperatures of $100{ }^{\circ} \mathrm{C}$, about $60 \%$ at $180{ }^{\circ} \mathrm{C}$, and finally about $95 \%$ at $260{ }^{\circ} \mathrm{C}$. The results suggest that the nanocomposites have a much higher oxidation resistance than metallic $\mathrm{Nb}$ and that the oxide layers on the nanocomposites are only about $1 \mathrm{~nm}$ up to $180{ }^{\circ} \mathrm{C}$. A more significant oxidation starts at temperatures above $180{ }^{\circ} \mathrm{C}$. The oxide thickness at $260{ }^{\circ} \mathrm{C}$ was estimated using the following approach: The $\mathrm{Nb3d}$ spectra (without Ar-ion etching) showed no $\mathrm{Nb}-\mathrm{Nb}$ bonding states of annealed $\mathrm{Nb}$ coatings, which means that the oxide was thicker than the information depth. In contrast, a weak $\mathrm{Nb}-\mathrm{C}$ contribution was observed on the nanocomposite coatings suggesting that the oxide in this case was thinner than the information depth. The information depth could be estimated to be $8.5 \mathrm{~nm}$ (Eq. (1) and $4 \lambda$ ), assuming an oxide with full coverage, an acquisition angle of $45^{\circ}$, and an attenuation length $\left(\lambda_{\mathrm{ox}}\right)$ of $3 \mathrm{~nm}$. This means that the oxide on the nanocomposite coatings after 15 -min annealing at $260{ }^{\circ} \mathrm{C}$ is less than $8.5 \mathrm{~nm}$. To estimate the oxide thickness at the highest temperature on the $\mathrm{Nb}$ coating, an initial minor sputter etch was carried out on this sample to remove approximately $1 \mathrm{~nm}$ of coating material $\left(500 \mathrm{eV} \mathrm{Ar}{ }^{+}, 1 \mathrm{~min}\right)$, and lastly sputter etching to a depth of approximately $20 \mathrm{~nm}\left(1 \mathrm{keV} \mathrm{Ar}^{+}, 10 \mathrm{~min}\right)$. The sputter rate of $\mathrm{Nb}-\mathrm{O}$, formed on the coatings, was determined by sputter removal of the oxide with its thickness known (from XPS analysis). The evolution of the oxygen to niobium atomic ratios $(\mathrm{O} / \mathrm{Nb})$ for the $\mathrm{Nb}$ and $\mathrm{NbC}_{0.8} / \mathrm{a}$ $\mathrm{C}_{24}: \mathrm{H}$ coatings at $260{ }^{\circ} \mathrm{C}$ is shown in the inset in Fig. 7. As can be seen, no indication of oxide is seen on either of the two samples. Consequently, the oxide thickness on the metallic $\mathrm{Nb}$ coating was estimated to be in the range of $8.5-20 \mathrm{~nm}$.

We further wanted to study the surface chemistry of $\mathrm{NbC}_{x} / \mathrm{a}-\mathrm{C}_{y}: \mathrm{H}$ coatings deposited using conditions which would mimic an industrial production scenario, where samples ideally should be transferred from the process chamber to atmosphere (i.e., 
ventilation) as quickly as possible to maximize throughput. The hypothesis, as well as concern, is that the surfaces of the coated components may then oxidize in air due to high substrate temperature upon ventilation ("venting temperature"). Additional samples were deposited on $\mathrm{Cu}-\mathrm{Sn} / \mathrm{Ni}$ substrates at $200{ }^{\circ} \mathrm{C}$, and these were then kept under vacuum (base pressure $10^{-4} \mathrm{~Pa}$ ) for shortened periods of time of 10,60 , or $300 \mathrm{~s}$ to dissipate different amounts of heat before exposure to atmosphere. All other conditions were as before. The choice of $200{ }^{\circ} \mathrm{C}$ is a tradeoff between a high substrate temperature, which is typically beneficial for properties of sputtered coatings, and to avoid adversely affecting the substrate material, e.g., due to softening of the Cu-Sn. At the time of ventilation, the measured surface temperatures of the samples were $190-210{ }^{\circ} \mathrm{C}$ for the two shortest times and $110{ }^{\circ} \mathrm{C}$ for the longest one (300 s). The temperatures quickly decreased under ambient conditions, which made the measurements somewhat uncertain given that Stefan-Boltzmann heat irradiation obeys a $\mathrm{T}^{4}$ relationship. Note also that temperatures should be affected by thermal mass and influenced by fixturing arrangements, meaning that the cooling times are specific for this experiment.

The bulk composition of the samples was determined to be $\mathrm{NbC}_{1.0} / \mathrm{a}-\mathrm{C}_{44}: \mathrm{H}$ using the same procedure as before. Figure 8 shows a plot of Nb3d spectra (Fig. 8a) and three 2D contour plots of the $\mathrm{C} 1 \mathrm{~s}$ region (Fig. 8b-d). Figure 8a shows that there are three Nb3d surface spectra for the three cooling times, and (a) $\mathrm{Nb3d}$

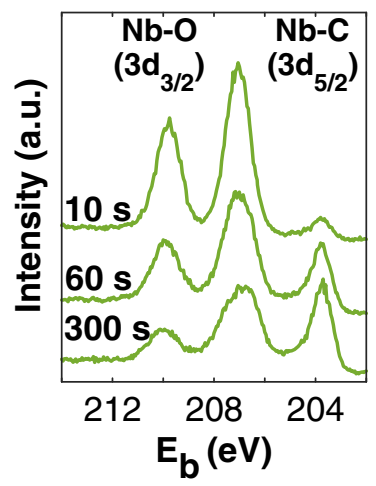

(b) $\mathrm{C} 1 \mathrm{~s}, 10 \mathrm{~s}$
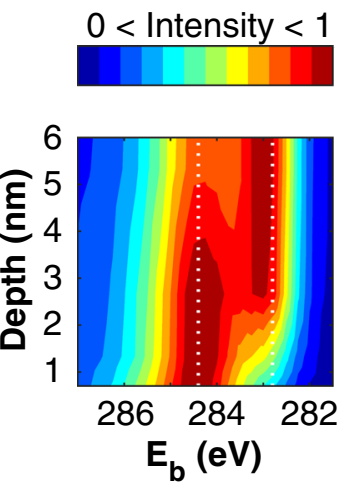

Figure $8 \mathrm{NbC}_{1.0} / \mathrm{a}-\mathrm{C}_{44}: \mathrm{H}$ samples were deposited by an identical deposition process and then kept under vacuum for different cooling times of 10,60 , or $300 \mathrm{~s}$, before exposure to atmosphere. a XPS Nb3d spectra for the different cooling times. No sputter etching was used. $\mathbf{b}-\mathbf{d}$ Contour plots of intensity from XPS C1s spectra in different colors as a function of binding energy and it is easy to realize that the cooling time prior to air exposure had direct consequences for the surface chemistry by comparing the $\mathrm{Nb}-\mathrm{O}$ intensities. Correspondingly, the coating cooled for only $10 \mathrm{~s}$ exhibited a thicker oxide, with only a small intensity due to $\mathrm{Nb}-\mathrm{C}$ bonding states in the Nb3d spectrum. In contrast, the longest cooling time resulted in a limited oxide growth of only $0.9 \mathrm{~nm}$, i.e., similar to that in Fig. 6. It can be concluded that the venting temperature is an important and influential parameter for the surface chemistry of carbide nanocomposites. An analogous effect has also been demonstrated for TiN [40]. Conversely, it may possible to reduce these oxides by vacuum annealing, as has been done for air-exposed $\mathrm{Ni}_{3} \mathrm{C} / \mathrm{a}-\mathrm{C}$ coatings [41]. The presence of $\mathrm{a}-\mathrm{C}$ phase may lower the reduction temperature of the oxide for the $\mathrm{Nb}-\mathrm{C}$ case, compared to the $\mathrm{Nb}$ case, via carbothermal reduction. This remains to be experimentally verified for these $\mathrm{Nb}-\mathrm{C}$ coatings, but is out of the scope of this report.

To further study the effect of surface oxidation, depth profiles of the $\mathrm{C} 1 \mathrm{~s}$ spectra were acquired from the three samples. The results are shown in Fig. $8 \mathrm{~b}-\mathrm{d}$, where the $\mathrm{C} 1 \mathrm{~s}$ intensity is represented by different colors as a function of estimated depth assuming an $\mathrm{Ar}^{+}$-etching rate of $1.3 \mathrm{~nm} \mathrm{~min}{ }^{-1}$. The first spectra were recorded at a depth of $0.7 \mathrm{~nm}$ to remove adsorbed surface contaminations (e.g., $\mathrm{H}_{2} \mathrm{O}$ and hydrocarbons). As can be seen, two features are present in the spectra: The $\mathrm{C}-\mathrm{C}$ peak at $284.4 \mathrm{eV}$ and the $\mathrm{C}-\mathrm{Nb}$ peak at $282.8 \mathrm{eV}$ (cf. Fig. 4a). An interesting observation is that (c) $\mathrm{C} 1 \mathrm{~s}, 60 \mathrm{~s}$
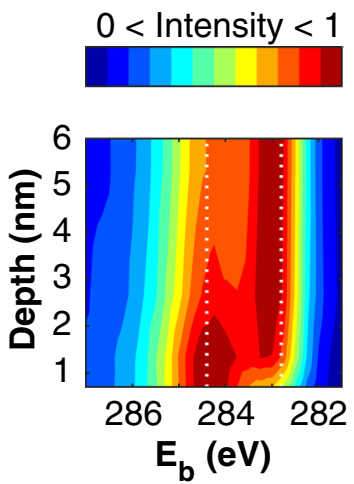

(d) $\mathrm{C} 1 \mathrm{~s}, 300 \mathrm{~s}$
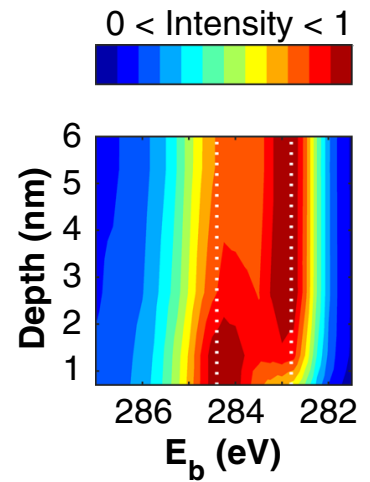

sputter depth for each cooling time in ascending order. Maps were interpolated from spectra obtained at depths of 0.7, 1.3, 2.7, 5.3, and $10.7 \mathrm{~nm}$ (500 eV Ar ${ }^{+}$etching). All hydrocarbon contamination was eliminated at $0.7 \mathrm{~nm}$. Dotted lines at 282.8 and $284.4 \mathrm{eV}$ correspond to $\mathrm{C}-\mathrm{Nb}$ and $\mathrm{C}-\mathrm{C}$ bonds, respectively. 
the oxidized surface region also contains an enrichment in $\mathrm{C}-\mathrm{C}$ bonds originating from a-C. The most oxidized sample in Fig. $8 \mathrm{~b}$ has a $\mathrm{C}-\mathrm{C}$ enrichment extending more than $3 \mathrm{~nm}$ into the coating, while the least oxidized sample in Fig. 8d has an enrichment depth of only $1 \mathrm{~nm}$. Note that these values are comparable to the oxide thickness. A similar trend was observed for the samples annealed using controlled conditions on the hot plate (discussed above), and the C-C enrichment was especially pronounced after annealing at $260{ }^{\circ} \mathrm{C}$, which is related to the extent of carbide oxidation (see Fig. 7) as will be discussed now.

The formation of additional a-C in the oxidized region can, in the present study, be explained by the following reaction (disregarding vacancies in the $\mathrm{NbC}_{x}$ ):

$2 x \mathrm{NbC}+\frac{5}{2} x \mathrm{O}_{2} \rightarrow x \mathrm{Nb}_{2} \mathrm{O}_{5}+2 x \mathrm{C}$

Note that Shimada [42] observed evolution of $\mathrm{CO}_{2}$ gas when annealing bulk $\mathrm{NbC}$ between 390 and $610{ }^{\circ} \mathrm{C}$. Shi et al. [43] also observed $\mathrm{CO}_{2}$ when annealing nanocrystalline $\mathrm{NbC}$ but only at temperatures above $350{ }^{\circ} \mathrm{C}$. Since we observed a carbon enrichment and that the annealing temperatures were not higher than $260{ }^{\circ} \mathrm{C}$, reaction (2) should be correct. Hence, it is clear that oxidation of the nanocomposite coatings not only leads to oxide formation, but must also lead to formation of free $C$ (unless the oxidation is carried out at a higher temperature). As will be discussed below, we propose that this additional presence of $C$ will influence the surface properties of the coatings.

\section{Coating properties}

\section{Electrical resistivity}

The resistivity is often obtained by measuring the sheet resistance and multiplying by coating thickness. In this case, the reactively sputtered layer was deposited on top of a metallic adhesion layer with much lower resistivity. Their separate contributions were resolved by a rudimentary parallel resistor model given by Eq. 3,

$\rho=R_{s} t=\frac{t_{a}+t_{b}}{t_{a} / \rho_{a}+t_{b} / \rho_{b}}$

where $\rho$ is resistivity, $R_{s}$ is the measured sheet resistance, $t$ is thickness, and the two indexes $a$ and $b$ denote the adhesion layer and the reactively sputtered layer, respectively. Values for $\rho_{b}$, hereafter simply referred to as the resistivity, are summarized in Table 1. The resistivity increased from $35 \mu \Omega \mathrm{cm}$ for metallic $\mathrm{Nb}$, up to about 500 and $1000 \mu \Omega \mathrm{cm}$ for $\mathrm{C} / \mathrm{Nb}$ ratios of 1.0 and 1.6 , respectively. Literature data for bulk $\mathrm{Nb}$ is $15 \mu \Omega \mathrm{cm}$, while the resistivity of bulk $\mathrm{NbC}_{x}$ spans from 40 up to $155 \mu \Omega \mathrm{cm}$ with higher values for a higher amount of carbon vacancies [44]. Higher resistivities for the coatings is expected and can principally be explained by scattering effects due to the small grain size or by electron tunneling through thin layers of a-C [45-47]. The present values were also compared to the previous $\mathrm{NbC}_{x} / \mathrm{a}-\mathrm{C}(\mathrm{H})$ coatings $[4,5]$. While there was very good agreement to the non-reactively sputtered coatings, the reactively $(: \mathrm{H})$ sputtered ones had much lower reported resistivities, around $200-400 \mu \Omega \mathrm{cm}$ [5]. However, those values may have been influenced by a thicker $\mathrm{Nb}$ adhesion layer. To summarize, prior to the contact resistance results, the coatings contained surface oxides as well as amorphous carbon and exhibited a (presumably) high hardness and relatively high resistivity. From a classical perspective, these conditions would indicate a far from optimal situation for the contact properties.
Table 1 Electrical contact resistance $R$ in $\mathrm{m} \Omega$ at $1 \mathrm{~N}$ load before and after 15-min annealing in air

\begin{tabular}{lllll}
\hline$R$ in $\mathrm{m} \Omega$ & $\mathrm{C} / \mathrm{Nb}=0$ & $\mathrm{C} / \mathrm{Nb}=0.8$ & $\mathrm{C} / \mathrm{Nb}=1.0$ & $\mathrm{C} / \mathrm{Nb}=1.6$ \\
\hline$R$, as dep. & 2700 & 310 & 63 & 76 \\
$R, 100{ }^{\circ} \mathrm{C}$ & 7400 & 910 & 73 & 300 \\
$R, 180{ }^{\circ} \mathrm{C}$ & 13000 & 860 & 53 & 390 \\
$R, 260{ }^{\circ} \mathrm{C}$ & 50000 & 39000 & 24000 & 33000 \\
$\rho(\mu \Omega \mathrm{cm})$ & 35 & 310 & 510 & 940 \\
\hline
\end{tabular}

The precision in contact resistance was about $10 \%$ for most samples (up to $30 \%$ for the most oxidized samples after annealing). Resistivity $\rho$ (see Eq. 3; as-deposited) is also included. The precision in resistivity measurements was $3 \%$ 


\section{Electrical contact resistance}

The contact resistance was obtained by vertically moving a coated sample toward a spring-loaded hemispherical $(d=1.2 \mathrm{~mm})$ gold-coated probe, establishing contact loads of $\sim 0$ to $1 \mathrm{~N}$, and then measuring the voltage drop (c.f. Fig. 1). Results for the set of annealed coatings are given in Table 1. As can be seen, the samples annealed to $260{ }^{\circ} \mathrm{C}$ all exhibited extremely high contact resistances. This can be explained by the rather thick oxide film on these samples as shown in Fig. 7. Furthermore, the metallic $\mathrm{Nb}$ coating exhibited higher contact resistances than any of the nanocomposite coatings. The lowest contact resistance was observed for the $\mathrm{NbC}_{0.8} / \mathrm{a}-\mathrm{C}_{24}: \mathrm{H}$ coating (corresponding to $\mathrm{C} / \mathrm{Nb}=1.0$ in Table 1) followed by the $\mathrm{NbC}_{0.9} / \mathrm{a}-\mathrm{C}_{44}: \mathrm{H}$ coating $(\mathrm{C} / \mathrm{Nb}=1.6$ in Table 1). A minimum in contact resistance at about $24 \%$ a-C:H constitutes a trend that is in experimental agreement with other studies on both nanocrystalline [28] as well as amorphous [3] nanocomposites.

It is evident that the contact resistance is affected by the oxide thickness. Figure 9 is a plot of the contact resistance as a function of mean oxide thickness for all samples in Table 1 as well as for the $\mathrm{NbC}_{1.00} / \mathrm{a}-\mathrm{C}_{44}: \mathrm{H}$ samples in Fig. 8 . The results strongly indicate that the contact resistance is exponentially dependent on the oxide thickness, but with an offset for each series of samples. It is interesting to note that the $\mathrm{NbC}_{1.00} / \mathrm{a}-\mathrm{C}_{44}: \mathrm{H}$ series (from the experiments with different cooling times and venting temperatures) exhibited a much lower contact resistance compared to, for example, the $\mathrm{NbC}_{0.9} / \mathrm{a}-\mathrm{C}_{44}: \mathrm{H}$ series. This can be due to that is was deposited at

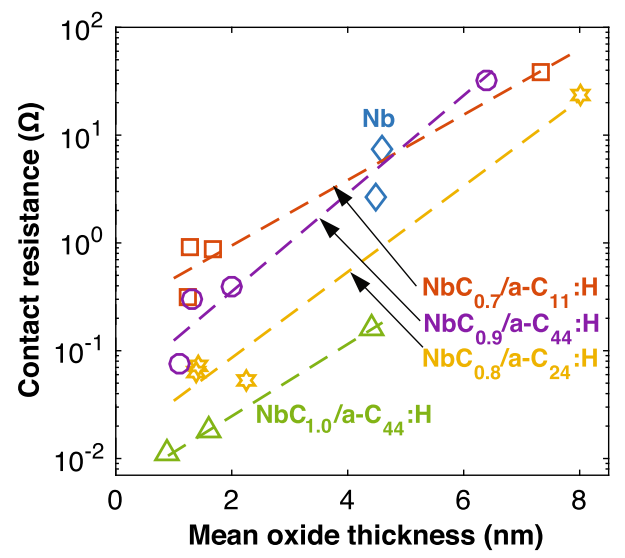

Figure 9 Contact resistance $(\log )$ at $1 \mathrm{~N}$ load versus mean oxide thickness. Dashed lines are exponential regressions.
$200{ }^{\circ} \mathrm{C}$ or due to an aging effect since the contact resistance of the $\mathrm{NbC}_{1.00} / \mathrm{a}-\mathrm{C}_{44}: \mathrm{H}$ series was measured only a few hours after deposition compared to a few months for all other series. It is not unlikely that the native passive films formed during sample storage in air-tight plastic containers. However, the passivation from the experimentally induced elevated temperatures far outweighs that of a much slower, but possible, aging process. A very important result in Fig. 9 is that oxide thickness alone cannot explain the contact resistance variations of the samples. For example, a number of samples have oxide thicknesses of about $1 \mathrm{~nm}$, but these samples exhibit contact resistance values ranging over two orders of magnitude $\left(10^{-2}-10^{0} \Omega\right)$. Consequently, some other factor must also play a crucial role in the contact behavior and the attention will now be on the a-C phase and contact mechanics.

Equation 4 is based on contact theory [9] and it is an adapted version of the power law describing the relationship between the contact resistance of a junction and the contact load when a sample is mated to an overlayer-free probe (gold). It states that

$R=c F^{-a}$

where $R$ is the contact resistance, $c$ is a constant that accounts for material properties, $F$ is the contact load, and the exponent $a$ should be equal to $1 / 2$ for an overlayer-free sample or equal to 1 in the presence of an overlayer [9]. For the overlayer model, the constant $c$ is given by Eq. 5,

$c=\rho d H$

where $\rho$ is the overlayer resistivity, $d$ is the overlayer thickness, and $H$ is the hardness of softest material (gold) [9]. The reason for hardness being in Eq. 5 is that conditions of plastic deformation between two contact members are assumed, which leads to Eq. 6,

$A_{\mathrm{c}}=\frac{F}{H}$

where $A_{\mathrm{c}}$ is the contact area. As the load increases, the contact area should increase, and consequently, the contact resistance should decrease. If the above equations actually are relevant for a nanocomposite gradient, overlayer can be debated, because the theory assumes that the size of the $a$-spot is small (normally of micron or submicron size) compared to the spread of a surrounding oxide [9]. Due to the small grains in the nanocomposites, it is not certain that this 
concept can be applied, and furthermore, the resistivity of the present overlayer should change as a function of depth. However, under the assumption that $c$ is constant, the focus will be on the load-dependency factor $F^{-a}$.

Figure 10 shows plots of contact resistance as a function of load for one $\mathrm{Nb}$ coating, the three $\mathrm{NbC}_{1.00} / \mathrm{a}-\mathrm{C}_{44}: \mathrm{H}$ coatings from the cooling experiments (c.f. Fig. 8), and one Au reference coating. Each curve has been fitted by a power law function according to Eq. 4. The Au reference had a load dependency of $F^{-0.51}$, as well as a very good quality fit, in good agreement with the overlayer-free system. For the $\mathrm{Nb}$ coating, with a $\mathrm{Nb}_{2} \mathrm{O}_{5}$ surface layer, the load dependency was $F^{-1.08}$, which is in good agreement with the overlayer model. For the nanocomposite coatings, the load dependencies were $F^{-1.41}$, $F^{-1.39}$, and $F^{-1.1}$, which overall are considered to deviate from the ideal case of $F^{-1}$. The fits are good but not perfect and at around $0.4 \mathrm{~N}$, the curves transition from a steep decrease in resistance into a region with a less steep decrease. The nanocomposite with the thinnest oxide exhibited an exponent close to -1 in agreement with a simple overlayer model, while the other two samples with thicker oxides exhibited exponents of about -1.4. The thicker oxides also

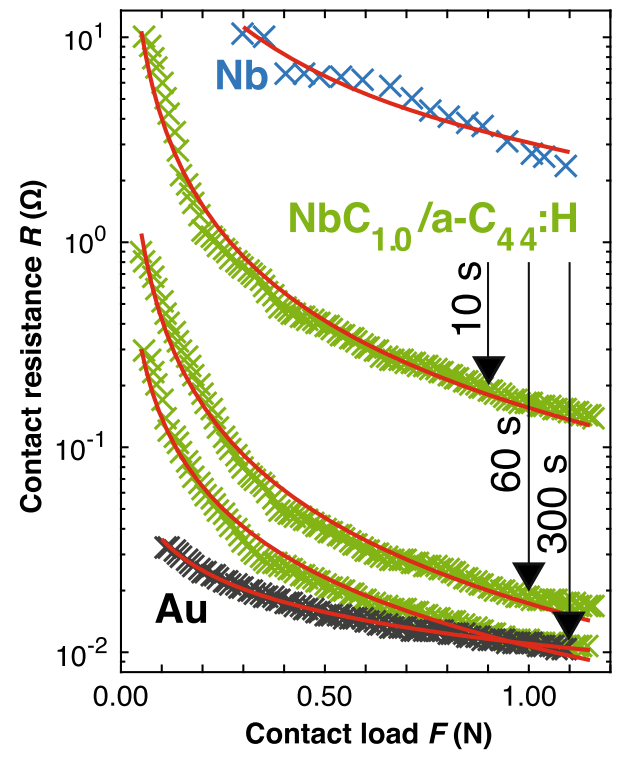

Figure 10 Contact resistance $R$ (log) versus contact load $F$ for one $\mathrm{Nb}$ coating, three nanocomposite $\mathrm{NbC}_{1.0} / \mathrm{a}-\mathrm{C}_{44}: \mathrm{H}$ coatings from the cooling experiments (see Fig. 8), and one Au coating. Dashed lines are power law regressions of type $R=c F^{-a}$ where $a_{\mathrm{Nb}}=1.08, \quad a_{10 \mathrm{~s}}=1.41, \quad a_{60 \mathrm{~s}}=1.39, \quad a_{300 \mathrm{~s}}=1.11, \quad$ and $a_{\mathrm{Au}}=0.51$. contained more free a-C formed during the oxidation in accordance with Eq. (2) and as demonstrated in Fig. 8. It is likely that the deviation from a $F^{-1}$ load dependence in Fig. 10 can indirectly be explained by differences in the mechanical properties of the overlayers, which result in differences in the conductive contact area.

Based on the presented results, the schematic model in Fig. 11 was devised. It illustrates a cross-sectional view of an electrical contact junction for three different coatings. In Fig. 11a, the coating has a coarse-grained structure with none to a small amount of a-C(:H) matrix. In Fig. 11b, the coating has medium-sized nanocrystalline $(10-100 \mathrm{~nm})$ grains and a medium amount of a-C(:H) matrix. In Fig. 11c, the coating has very small nanocrystalline $(<10 \mathrm{~nm})$ grains and a high amount of a-C(:H) matrix. These three cases roughly correspond to the $\mathrm{NbC}_{0.7} / \mathrm{a}-\mathrm{C}_{11}: \mathrm{H}, \mathrm{NbC}_{0.8} / \mathrm{a}-\mathrm{C}_{24}: \mathrm{H}$, and $\mathrm{NbC}_{0.9} / \mathrm{a}-\mathrm{C}_{44}: \mathrm{H}$ coatings in this study, although the model should be considered general. The numbers in Fig. 11, from 1 to 7, represent important areas in the contacting process. In the first case (a), there is a widespread oxide covering the junction, and in most mechanical contact points there will be no breakthrough of this oxide (1) and only minor breakthrough (2) in a few areas. This gives rise to a high electrical contact resistance, in correspondence with the contact resistances observed for the $\mathrm{NbC}_{0.7} / \mathrm{a}-\mathrm{C}_{11}: \mathrm{H}$ and $\mathrm{Nb}$ coatings (c.f. Fig. 9; Table 1). Note also that the oxide starts to nucleate at multiple sites and this effect gives rise to a serrated oxide accompanied by the release of carbon in nearby region (c.f. reaction 2 in "Surface characterization of coatings" section). In the next case (b), the grains are much smaller and most importantly, many of the ones near the surface are covered by the $\mathrm{a}-\mathrm{C}(\mathrm{H})$ matrix. When the counterpart mates to the coating the thin surface layer of carbon will give way and hence a conductive junction is established (3). Grains not covered by a-C matrix (4) are highly susceptible to oxidation, especially considering their small size, and will present a thick oxide layer which inhibits a conductive junction. Furthermore, the release of highly resistive carbon (compared to the resistivity of $\mathrm{NbC}$ ) should also be the cause for the unusual load dependencies $\left(F^{-a}\right)$ as discussed above and observed in Fig. 10. In the last case (c), there is a high content of a-C matrix phase, and in area (5), there will be a conductive junction, just as in area (3), and there will also be oxidation of grains exposed to air in area (6), just as in area (4). However, these grains are 
(a)

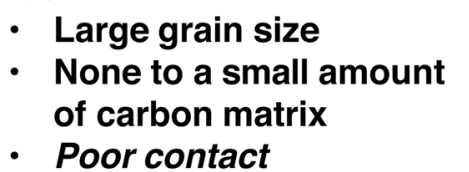

- Poor contact

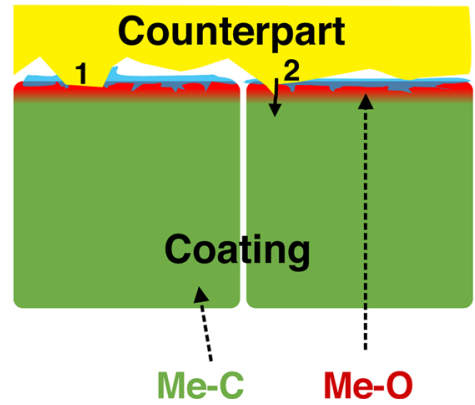

(b)
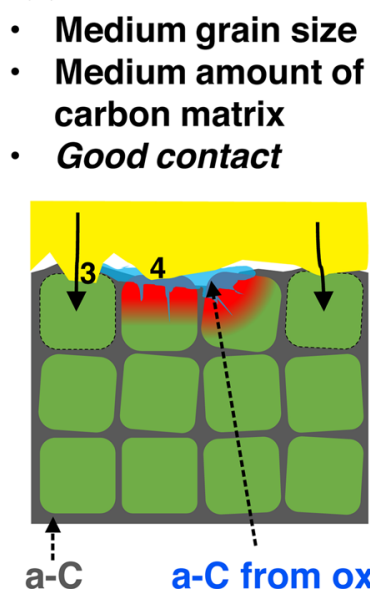

Figure 11 A schematic model illustrating the structure and chemistry of three different coatings in an electrical contact situation. The solid arrows show where current flows. a Represents a coarse-grained coating with large grains and none to a small amount of carbon matrix (a-C). b Represents a coating with medium-sized grains and a medium amount of carbon matrix. c Represents a coating with small grains and a high amount of carbon matrix. Numbers 1-7 represent the following. (1) A widespread oxide prevents conductive junctions. (2) A small

very small and have a higher surface/volume ratio, suggesting that they get oxidized to a greater extent. The combination of differences in amount of a-C matrix phase and grain size explains the very similar $\mathrm{Nb}-\mathrm{O}$ bond fractions observed in Fig. 7 for the carboncontaining samples. The model also explains how there could be very significant intensity from $\mathrm{Nb}-\mathrm{C}$ bonds in the ARXPS data even at grazing angles (c.f. Fig. 5), i.e., there must have been carbide phase very close to the surface. Finally, in area (7) the a-C layer has become too thick and the counterpart cannot establish electrical contact to the carbide grain below. This effect explains why the contact resistance is seen to increase when the $\mathrm{C} / \mathrm{Nb}$ ratio gets high (c.f. Table 1 ), and it consequently explains the optimum in contact resistance at $24 \%$ a-C as well. With regard to the mean matrix thickness, as was calculated above, the suggested model implies that the ratio of mean matrix thickness to grain size is important for the contact properties of $n c-M_{x} / a-C(: H)$. Based on the obtained experimental data, a minimum in contact resistance was observed when the mean matrix thickness was $6 \%$ of the grain size. It is suggested, from the optimization point of view, that deposition conditions should be tuned to give such a microstructure. (c)

\section{- Small grain size \\ - High amount of carbon matrix \\ - Medium contact}

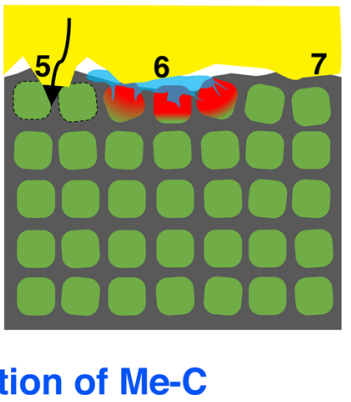

mechanical disruption of the oxide film occurs, allowing for some current to flow. (3) The carbon matrix protects carbide grains from oxidation. When the counterpart mates to the coating, the thin surface layer of carbon gives way and a conductive junction is established. (4) Carbide grains not covered by the carbon matrix are easily oxidized. (5) See number 3. (6) See number 4, with the addition the smaller grains will oxidize to relatively further extent. (7) The carbon layer is too thick and prevents a conductive junction.

A final note is that Fig. 10 confirms that a $\mathrm{NbC}_{x} / \mathrm{a}$ $\mathrm{C}: \mathrm{H}$ nanocomposite deposited under the right circumstances, i.e., that minimize the oxide layer, can have similar contact resistance as Au coatings at a contact load of $1 \mathrm{~N}$ in the present measurement setup. This result demonstrates a significant promise for using this material in low-load electrical contact applications. Further studies are, however, required to study the corrosion resistance in relevant tests, as well as to study durability and aging.

\section{Conclusions}

Nanocrystalline niobium carbide/hydrogenated amorphous carbon $\left(\mathrm{NbC}_{x} / \mathrm{a}-\mathrm{C}_{y}: \mathrm{H}\right)$ nanocomposite coatings were deposited by high-rate reactive industrial magnetron sputtering, and the coating microstructure, surface chemistry, and electrical contact resistance at low contact loads were studied. The mean oxide thickness on the nanocomposites was found to be $1 \mathrm{~nm}$ compared to $4 \mathrm{~nm}$ for metallic $\mathrm{Nb}$. Annealing experiments up to $260{ }^{\circ} \mathrm{C}$ in air resulted in thicker oxides of up to $8 \mathrm{~nm}$ according to XPS. Upon oxidation, the $\mathrm{NbC}_{x}$ grains released $\mathrm{C}$ in 
their vicinity, leading to a surface layer enriched in $\mathrm{C}$ and $\mathrm{Nb}_{2} \mathrm{O}_{5}$ although the bulk chemistry below the surface layer remained intact. The electrical contact resistance was exponentially dependent on the mean oxide thickness at a contact load of $1.0 \mathrm{~N}$. However, coatings with similar mean oxide thickness exhibited two orders of magnitude difference in contact resistance, suggesting that some other factor played an important role. It was found that the a-C:H matrix acted as an oxidation barrier on the surface, effectively protecting the carbide grains from oxidation. In an electrical contact configuration, a counterpart penetrated this a-C:H layer and made electrical contact to non-oxidized $\mathrm{NbC}_{x}$ grains, which resulted in a very low electrical contact resistance. Too much of the a-C:H matrix made the insulating barrier too thick and led to higher contact resistance. The best sample with very little oxide had a contact resistance that was comparable to $\mathrm{Au}$ at a load of $1 \mathrm{~N}$. Further studies are, however, required to evaluate corrosion resistance as well as durability and aging to evaluate this material for low-load electrical contact applications.

\section{Acknowledgements}

We thank Dr. Pedro Berastegui at Uppsala University for doing the X-ray diffraction measurements. The Swedish Foundation for Strategic Research is acknowledged for financial support through the program ProViking, as well as through the Synergy Grant FUNCASE, Functional Carbides and Advanced Surface Engineering. VINN Excellence Center in research and innovation on Functional Nanoscale Materials (FunMat) by the Swedish Governmental Agency for Innovation Systems is acknowledged for financial support. The Swedish Research Council (VR 2011-3492) is acknowledged for financial support.

\section{Compliance with ethical standards}

Conflict of interest The authors declare that they have no conflicts of interest.

Open Access This article is distributed under the terms of the Creative Commons Attribution 4.0 International License (http://creativecommons.org/ licenses/by/4.0/), which permits unrestricted use, distribution, and reproduction in any medium, provided you give appropriate credit to the original author(s) and the source, provide a link to the Creative Commons license, and indicate if changes were made.

\section{References}

[1] Lewin E, Wilhelmsson O, Jansson U (2006) Nanocomposite nc-TiC/a-C thin films for electrical contact applications. J Appl Phys 100:54303. doi:10.1063/1.2336302

[2] Lewin E, Olsson E, André B, Joelsson T, Öberg Å, Wiklund U, Ljungcrantz H, Jansson U (2009) Industrialisation study of nanocomposite nc-TiC/a-C coatings for electrical contact applications. Plasma Process Polym 6:S928-S934. doi:10. 1002/ppap.200932303

[3] Nygren K, Samuelsson M, Flink A, Ljungcrantz H, Kassman Rudolphi Å, Jansson U (2014) Growth and characterization of chromium carbide films deposited by high rate reactive magnetron sputtering for electrical contact applications. Surf Coat Technol 260:326-334. doi:10.1016/j.surfcoat.2014.06. 069

[4] Nedfors N, Tengstrand O, Lewin E, Furlan A, Eklund P, Hultman L, Jansson U (2011) Structural, mechanical and electrical-contact properties of nanocrystalline-NbC/amorphous-C coatings deposited by magnetron sputtering. Surf Coat Technol 206:354-359. doi:10.1016/j.surfcoat.2011.07. 021

[5] Nedfors N, Tengstrand O, Flink A, Andersson AM, Eklund P, Hultman L, Jansson U (2014) Reactive sputtering of $\mathrm{NbC}_{\mathrm{x}}$-based nanocomposite coatings: an up-scaling study. Surf Coat Technol 253:100-108. doi:10.1016/j.surfcoat. 2014.05.021

[6] Lewin E (2009) Design of carbide-based nanocomposite coatings. Acta Universitatis Upsaliensis

[7] Öberg Å, Kassman Å, André B, Wiklund U, Lindquist M, Lewin E, Jansson U, Högberg H, Joelsson T, Ljungcrantz H (2009) Conductive nanocomposite ceramics as tribological and electrical contact materials. Eur Phys J Appl Phys 49:22902. doi:10.1051/epjap/2009122

[8] Eklund P, Emmerlich J, Högberg H, Wilhelmsson O, Isberg P, Birch J, Persson POA, Jansson U, Hultman L (2005) Structural, electrical, and mechanical properties of nc-TiC/aSiC nanocomposite thin films. J Vac Sci Technol B Microelectron Nanometer Struct 23:2486. doi:10.1116/1.2131081

[9] Slade PG (2013) Electrical contacts: principles and applications, 2nd edn. Taylor \& Francis, Abingdon

[10] Greenwood JA (1966) Constriction resistance and the real area of contact. Br J Appl Phys 17:1621-1632. doi:10.1088/ 0508-3443/17/12/310 
[11] Sawada S, Shimizu K, Shimada S, Hattori Y (2010) Prediction of electrical contact resistance of tin-plated and silver-plated terminals. SEI Tech Rev 71:37-43

[12] Zhang P, Lau YY, Tang W, Gomez MR, French DM, Zier JC, Gilgenbach RM (2011) Contact resistance with dissimilar materials: bulk contacts and thin film contacts. IEEE Holm Conf Electr Contacts. doi:10.1109/HOLM.2011. 6034777

[13] Mercier D, Mandrillon V, Holtz A, Volpi F, Verdier M, Bréchet Y (2012) Quantitative evolution of electrical contact resistance between aluminum thin films. IEEE Holm Conf Electr Contacts. doi:10.1109/HOLM.2012.6336550

[14] Timsit RS (1999) Electrical contact resistance: properties of stationary interfaces. IEEE Trans Compon Packag Technol 22:85-98. doi:10.1109/6144.759357

[15] Charitidis CA (2010) Nanomechanical and nanotribological properties of carbon-based thin films: a review. Int J Refract Met Hard Mater 28:51-70. doi:10.1016/j.ijrmhm.2009.08.003

[16] Leyland A, Matthews A (2004) Design criteria for wearresistant nanostructured and glassy-metal coatings. Surf Coat Technol 177-178:317-324. doi:10.1016/j.surfcoat.2003.09. 011

[17] Cao Y, Allameh S, Nankivil D, Sethiaraj S, Otiti T, Soboyejo W (2006) Nanoindentation measurements of the mechanical properties of polycrystalline $\mathrm{Au}$ and $\mathrm{Ag}$ thin films on silicon substrates: effects of grain size and film thickness. Mater Sci Eng A 427:232-240. doi:10.1016/j.msea.2006.04.080

[18] Leyland A, Matthews A (2000) On the significance of the $\mathrm{H} / \mathrm{E}$ ratio in wear control: a nanocomposite coating approach to optimised tribological behaviour. Wear 246:1-11. doi:10. 1016/S0043-1648(00)00488-9

[19] Eklund P, Virojanadara C, Emmerlich J, Johansson LI, Högberg H, Hultman L (2006) Photoemission studies of $\mathrm{Ti}_{3} \mathrm{SiC}_{2}$ and nanocrystalline-TiC/amorphous-SiC nanocomposite thin films. Phys Rev B 74:45417. doi:10.1103/Phys RevB.74.045417

[20] Williamson GK, Hall WH (1953) X-ray line broadening from filed aluminium and wolfram. Acta Metall 1:22-31. doi:10.1016/0001-6160(53)90006-6

[21] Díaz J, Paolicelli G, Ferrer S, Comin F (1996) Separation of the $\mathrm{sp}^{3}$ and $\mathrm{sp}^{2}$ components in the $\mathrm{C} 1 \mathrm{~s}$ photoemission spectra of amorphous carbon films. Phys Rev B 54:8064-8069. doi:10.1103/PhysRevB.54.8064

[22] Hueso JL, Espinós JP, Caballero A, Cotrino J, GonzálezElipe AR (2007) XPS investigation of the reaction of carbon with $\mathrm{NO}, \mathrm{O}_{2}, \mathrm{~N}_{2}$ and $\mathrm{H}_{2} \mathrm{O}$ plasmas. Carbon 45:89-96. doi:10.1016/j.carbon.2006.07.021

[23] Boehm HP (2002) Surface oxides on carbon and their analysis: a critical assessment. Carbon 40:145-149. doi:10. 1016/S0008-6223(01)00165-8
[24] Halbritter J, Darlinski A (1987) Angle resolved XPS studies of oxides at $\mathrm{Nb}-, \mathrm{NbN}-, \mathrm{NbC}-$ and $\mathrm{Nb}_{3} \mathrm{Sn}$ surfaces. IEEE Trans Magn 23:1381-1384. doi:10.1109/TMAG.1987. 1065079

[25] Seah MP, Dench WA (1979) Quantitative electron spectroscopy of surfaces: a standard data base for electron inelastic mean free paths in solids. Surf Interface Anal 1:2-11. doi:10.1002/sia.740010103

[26] Straumanis ME, Zyszczynski S (1970) Lattice parameters, thermal expansion coefficients and densities of $\mathrm{Nb}$, and of solid solutions $\mathrm{Nb}-\mathrm{O}$ and $\mathrm{Nb}-\mathrm{N}-\mathrm{O}$ and their defect structure. J Appl Crystallogr 3:1-6. doi:10.1107/S002188 987000554X

[27] Onoprienko AA, Ivashchenko VI, Timofeeva II, Sinelnitchenko AK, Butenko OA (2016) Experimental and theoretical investigation of $\mathrm{Nb}-\mathrm{Si}-\mathrm{C}$ films. Surf Coat Technol 300:35-41. doi:10.1016/j.surfcoat.2016.05.007

[28] Jansson U, Lewin E (2013) Sputter deposition of transitionmetal carbide films - a critical review from a chemical perspective. Thin Solid Films 536:1-24. doi:10.1016/j.tsf.2013. 02.019

[29] Zhang K, Wen M, Meng QN, Hu CQ, Li X, Liu C, Zheng WT (2012) Effects of substrate bias voltage on the microstructure, mechanical properties and tribological behavior of reactive sputtered niobium carbide films. Surf Coat Technol 212:185-191. doi:10.1016/j.surfcoat.2012.09.046

[30] Storms EK, Krikorian NH (1959) The variation of lattice parameter with carbon content of niobium carbide. J Phys Chem 63:1747-1749. doi:10.1021/j150580a042

[31] Lewin E, Råsander M, Klintenberg M, Bergman A, Eriksson O, Jansson U (2010) Design of the lattice parameter of embedded nanoparticles. Chem Phys Lett 496:95-99. doi:10.1016/j.cplett.2010.07.013

[32] Zehnder T, Schwaller P, Munnik F, Mikhailov S, Patscheider J (2004) Nanostructural and mechanical properties of nanocomposite nc-TiC/a-C:H films deposited by reactive unbalanced magnetron sputtering. J Appl Phys 95:4327. doi:10.1063/1.1650898

[33] Ferrari AA, Kleinsorge B, Adamopoulos G, Robertson J, Milne W, Stolojan V, Brown L, LiBassi A, Tanner B (2000) Determination of bonding in amorphous carbons by electron energy loss spectroscopy, Raman scattering and X-ray reflectivity. J Non Cryst Solids 266-269:765-768. doi:10. 1016/S0022-3093(00)00035-1

[34] Grundner M, Halbritter J (1980) XPS and AES studies on oxide growth and oxide coatings on niobium. J Appl Phys 51:397-405. doi:10.1063/1.327386

[35] Darlinski A, Halbritter J (1987) Angle-resolved XPS studies of oxides at $\mathrm{NbN}, \mathrm{NbC}$, and $\mathrm{Nb}$ surfaces. Surf Interface Anal 10:223-237. doi:10.1002/sia.740100502 
[36] Kuznetsov MV, Razinkin AS, Shalaeva EV (2009) Photoelectron spectroscopy and diffraction of surface nanoscale $\mathrm{NbO} / \mathrm{Nb}(110)$ structures. J Struct Chem 50:514-521. doi:10. 1007/s10947-009-0079-y

[37] Daccà A, Gemme G, Mattera L, Parodi R (1998) XPS analysis of the surface composition of niobium for superconducting RF cavities. Appl Surf Sci 126:219-230. doi:10. 1016/S0169-4332(97)00790-3

[38] Fadley CS (1984) Angle-resolved X-ray photoelectron spectroscopy. Prog Surf Sci 16:275-388. doi:10.1016/00796816(84)90001-7

[39] Tengstrand O, Nedfors N, Andersson M, Lu J, Jansson U, Flink A, Eklund P, Hultman L (2013) Beam-induced crystallization of amorphous $\mathrm{Me}-\mathrm{Si}-\mathrm{C}(\mathrm{Me}=\mathrm{Nb}$ or $\mathrm{Zr})$ thin films during transmission electron microscopy. MRS Commun 3:151-155. doi:10.1557/mrc.2013.31

[40] Greczynski G, Mráz S, Hultman L, Schneider JM (2016) Venting temperature determines surface chemistry of magnetron sputtered TiN films. Appl Phys Lett. doi:10.1063/1. 4940974

[41] Bayer BC, Bosworth DA, Michaelis FB, Blume R, Habler G, Abart R, Weatherup RS, Kidambi PR, Baumberg JJ, KnopGericke A, Schloegl R, Baehtz C, Barber ZH, Meyer JC, Hofmann S (2016) In situ observations of phase transitions in metastable nickel (carbide)/carbon nanocomposites. J Phys Chem C 120:22571-22584. doi:10.1021/acs.jpcc. $6 \mathrm{~b} 01555$

[42] Shimada S (1994) A kinetic and thermoanalytical study on oxidation of powder and single-crystal samples of niobium carbide. Oxid Met 42:357-373. doi:10.1007/BF01046755

[43] Shi L, Gu Y, Chen L, Yang Z, Ma J, Qian Y (2005) Synthesis and oxidation behavior of nanocrystalline niobium carbide. Solid State Ion 176:841-843. doi:10.1016/j.ssi.2004.11.003

[44] Allison CY, Modine FA, French RH (1987) Optical and electrical properties of niobium carbide. Phys Rev B 35:2573-2582. doi:10.1103/PhysRevB.35.2573

[45] Abad MD, Sánchez-López JC, Cusnir N, Sanjines R (2009) WC/a-C nanocomposite thin films: optical and electrical properties. J Appl Phys 105:33510. doi:10.1063/1.3060717

[46] Sedláčková K, Lobotka P, Vávra I, Radnóczi G (2005) Structural, electrical and magnetic properties of carbonnickel composite thin films. Carbon 43:2192-2198. doi:10. 1016/j.carbon.2005.03.035

[47] Bozhko A, Takagi T, Takeno T, Shupegin M (2004) Electron transport in amorphous carbon-silicon nanocomposites containing Nb. Jpn J Appl Phys Part 1 43:7566-7571. doi:10. 1143/JJAP.43.7566 